\title{
Leakage Characteristic Identification of Labyrinth Seals on Reciprocating Piston through Transient Simulations
}

\author{
Lingzi Wang, ${ }^{1}$ Jianmei Feng $\mathbb{C D}^{1}{ }^{1}$ Mingfeng Wang, ${ }^{2}$ Zenghui $\mathrm{Ma}^{2}$ and Xueyuan Peng ${ }^{1}$ \\ ${ }^{1}$ School of Energy and Power Engineering, Xi'an Jiaotong University, Xi'an 710049, China \\ ${ }^{2}$ Operation District of Hutubi Gas Storage, PetroChina Xinjiang Oilfield Company, Hutubi, Xinjiang 831200, China \\ Correspondence should be addressed to Jianmei Feng; jmfeng@xjtu.edu.cn
}

Received 14 April 2019; Revised 16 August 2019; Accepted 30 August 2019; Published 25 September 2019

Academic Editor: Sébastien Poncet

Copyright (c) 2019 Lingzi Wang et al. This is an open access article distributed under the Creative Commons Attribution License, which permits unrestricted use, distribution, and reproduction in any medium, provided the original work is properly cited.

In the reciprocating labyrinth piston compressor, the characteristic of the internal leakage is crucial for the leakage management and performance improvement of the compressor. However, most of the published studies investigated the rotor-stator system, and those who study the reciprocating piston-cylinder system basically focus on the effects of the geometrical parameters. These conclusions could not directly be applied to predict the real-time leakage flow rate through the labyrinth seal because of the fast reciprocating motion of the piston, which will cause continually pressure change in two compression chambers, and then the pressure fluctuation will affect the flow through the labyrinth seal. A transient simulation model employing the multiscale dynamic mesh, which considers the effect of the reciprocating motion of the piston in the cylinder, is established to identify the characteristics of the internal leakage. This model was verified by a specially designed compressor, and the influence of various parameters was analyzed in detail. The sealing performance decreased linearly with the increase in the pressure ratio, and higher pressure inlet leads to higher leakage flow under the same pressure ratio. The labyrinth seal performance positively correlated to the increase of the rotational speed. Leakage characteristics of five working mediums were carried out, and the results indicated that the relative leakage decreased with an increase in the relative molecular mass. From this study, the realistic internal leakage flow rate under different operating parameters in the reciprocating labyrinth piston compressor could be predicated.

\section{Introduction}

The labyrinth seal is contact-free, thus allowing the compression of high-purity gases. This characteristic also eliminates lubrication oil expenses and inefficiencies from bearings, a crankshaft system, and gearbox [1]. Optimizing the labyrinth-reciprocating compressor will facilitate utilization of the labyrinth seal in more conditions; thus, the study of the effect of labyrinth cavity structure parameters and operation parameters on sealing performance is of great significance.

Many researchers [2-6] have explored the method of calculating labyrinth seal flow. Currently, the main research methods for labyrinth leakage are the thermodynamic theory analysis, numerical analysis method, leakage measurements, and flow visualization method. However, many of these studies investigated the mechanism in rotary machinery [7-14]. Kim and Cha [15] combined the method of CFD and theory analysis to study the flow pattern within the labyrinth seal and discussed the effect of structural arrangement and pressure ratio on sealing efficiency. They discovered that the efficiency of the stepped labyrinth seal increased when labyrinth clearance increased. Zhao et al. [16] investigated the effect of the cavity structure parameters on the leakage rate. Bozzi et al. [17] presented a detailed analysis and discussion on heat transfer in the labyrinth seal.

In the labyrinth-reciprocating compressor, annular labyrinth grooves were machined around the piston, so the labyrinth channel formed between the piston and cylinder wall. Figure 1 is the sectional view of a double-acting labyrinth-reciprocating compressor. A guide ring is required in the labyrinth compressor to keep the piston moving vertically in the cylinder. The motion of the reciprocating piston is not like that in a rotary machine. Though the mechanisms 


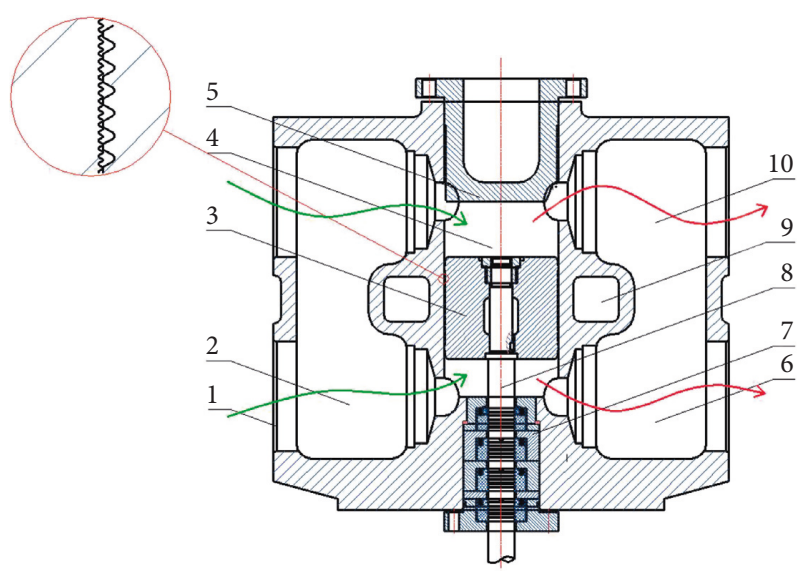

FIgUre 1: The sectional view of the labyrinth-reciprocating compressor. (1) Inlet; (2) suction chamber; (3) piston; (4) compression chamber; (5) end cap; (6) discharge chamber; (7) packing; (8) piston rod; (9) cooling water; (10) compression chamber.

of the labyrinth seal in a turbomachine are similar in a reciprocating piston compressor, the movement of the piston will affect the flow field in the labyrinth seal and some optimized design, such as the stepped labyrinth, cannot be applied in the reciprocating compressor.

With respect to the labyrinth piston machine, Cheng et al. $[18,19]$ introduced a new electromagnetic centering system replacing the traditional supporting structure to precisely center the piston and proposed a new numerical method to study the piston's dynamic behavior. Tang et al. [20] simulated the effect of the labyrinth seal characteristics, including tooth angle, sealing clearance, and cavity depth. Schaller et al. [21] and Feng et al. [22] numerically and experimentally investigated the effects of the geometrical parameters and shapes of labyrinth seals on the sealing performance. Graunke and Ronnert [23] researched the dynamic behavior inside the labyrinth compressor and discovered that labyrinth leakage correlated proportionally to the clearance, rotational speed, and pressure difference; however, the leakage was only minimally progressive with the eccentricity.

Because of the reciprocating motion of the piston, the pressure on each side of the labyrinth seal is dynamically changing, but the dynamic simulation research on the labyrinth-reciprocating compressor is still limited currently and needs further development. In this study, to simulate the actual movement of the reciprocating piston labyrinth compressor, a CFD model with multiscale dynamic mesh was applied. The mechanism of the labyrinth seal flow field was studied, and the effects of operating parameters such as pressure, rotational speed, clearance volume, and working medium on sealing performance in the reciprocating labyrinth piston compressor were presented based on the transient simulation results.

\section{Physical Model and Experimental System}

For the purpose of understanding the effect of the moving piston to the pressure and velocity field, the transient motion of piston has to been performed, so the transient-state CFD method was adopted.
Firstly, the two-dimensional (2D) simulation and three-dimensional (3D) simulation were compared. The grid generation method and the numerical approaches were all the same. The maximum difference between these two models was $1.7 \%$ for the leakage mass flow rate, which is the character that mostly concerned in this study. The simulation speed of the $2 \mathrm{D}$ model was 126 times faster than that of the 3D model. When finishing one reciprocating period, a $2 \mathrm{D}$ model would save more than two weeks' time. Thus, the 2D model was adopted in this study as it can also accurately identify the characteristics of the flow field when taking no account of the eccentric and incline of the piston. The details of this model were presented as follows.

2.1. Physical Model and Dynamic Mesh. The simplified physical model is shown in Figure 2. The piston rod occupies limited volume in the compression cavity with an insignificant impact on the performance of labyrinth seal, and the existence of the piston rod will divide the bottom compression chamber into two independent closed areas, which will mislead the pressure formation process in the compression chamber, so the piston rod was not included in this model. The flow area of the valve and the valve clearance were converted to the $2 \mathrm{D}$ model based on the rule of keeping the same mass flow rate as that in the real compressor. Ring valves were applied in this model, which will open when the actual exhaust and inlet pressures were higher than the theoretic exhaust and inlet pressures, respectively.

In the labyrinth compressor model, various parts have magnitude differences in scale. The labyrinth clearance, the narrowest channel, is $0.15 \mathrm{~mm}$, and the valve flow area, that is the valve opening height in this model, is $1.40 \mathrm{~mm}$. The larger structures, such as the compression chambers in the top and the bottom, have a length and width of approximately $150 \mathrm{~mm}$. The height of the suction and discharge valve chambers is approximately $400 \mathrm{~mm}$. Thus, meshes were installed, respectively, in different parts and then combined together to accurately model the whole flow field, as shown in Figure 2. The division of each part and the setting of mesh type referred to our former study [22]. Triangle meshes were generated in labyrinth seal to fit the cavity shape and the meshes in other zones were quadrangular meshes. Mesh independence is also carried out to achieve a balance between discretion error and calculation time. The mass flow rate and pressure distribution are used as references to check mesh independence. When the mesh scales were set to $0.20 \mathrm{~mm}$ for the labyrinth channel, it is suitable for presenting the flow characteristic. The mesh sizes for other parts were set according to the dimension ratio to the labyrinth seal and the data transmission possibility through the interface. The grid height for the valve area, the two compression chambers, the air valve clearance volume, and the intake and exhaust chamber was set to $0.50 \mathrm{~mm}$, $1.00 \mathrm{~mm}, 1.00 \mathrm{~mm}$, and $5.00 \mathrm{~mm}$, respectively.

The grid in the seal was set to move up and down accordingly with the piston in the cylinder, and their shapes and sizes remained unchanged. The grid in the top and 


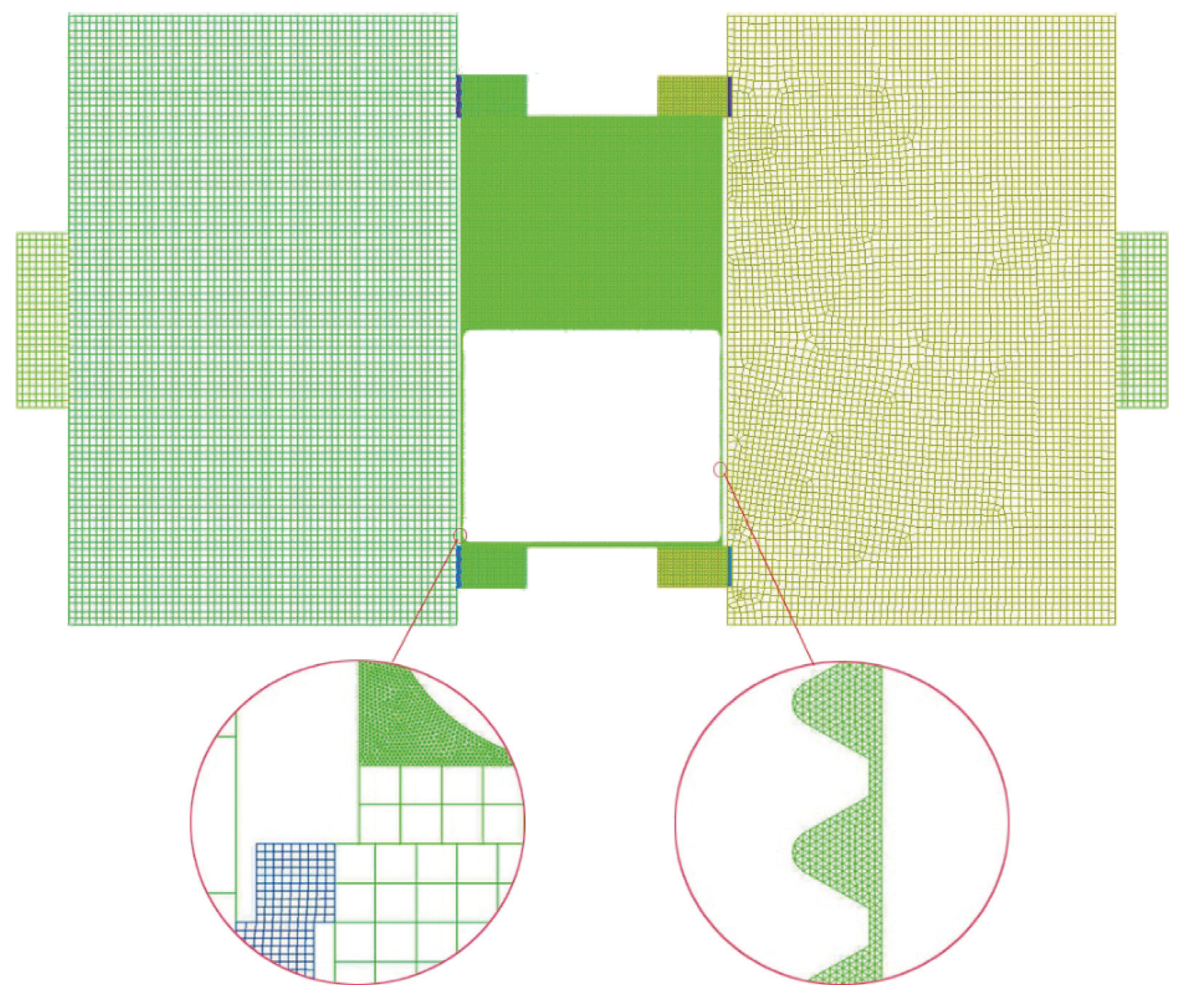

FIGURE 2: Simplified geometrical structure and mesh of the flow field.

bottom of the compression chamber was updated by the method of layering.

\subsection{Numerical Methodology. The Reynolds-Averaged} Navier-Stokes equations were employed to solve the transient flow in the computational domain. The effect of turbulence is considered using realizable $k-\varepsilon$ model, which was proved to be more suitable to simulate the flow field which contains swirl flow [24]. Flow near the wall was treated with standard wall functions.

The movement of the piston is calculated according to the following equation:

$$
v_{P}=\frac{\operatorname{Sn} \pi}{60}\left(\sin \theta+\frac{\lambda}{2} \frac{\sin 2 \theta}{\sqrt{1-\lambda^{2} \sin ^{2} \theta}}\right) .
$$

Boundary conditions were set in combination with the actual conditions. The atmospheric pressure was set to the intake pressure, $0.1 \mathrm{MPa}$, with a turbulence intensity of $5 \%$. The exhaust pressure was set according to different pressure ratios $(\varepsilon)$. The temperature at the intake side, equal to the environment temperature, is $300 \mathrm{~K}$. The outer wall of the cylinder directly contacted the cooling water, which circulated timely and can quickly remove heat from the cylinder wall, so the outside cylinder wall was set to $300 \mathrm{~K}$, equal to the temperature of the cooling water, and the high-pressure outlet temperature was based on practical experience, typically $300 \mathrm{~K}$ to $330 \mathrm{~K}$ with a compression ratio of 3 to 8 .

The equations were solved by employing the Pressure Implicit with Splitting of Operators (PISO). The secondorder scheme was used for pressure discretization, and the
QUICK scheme was applied for momentum discretization. The time step was chosen as the length of time that the crank rotates $0.25^{\circ}$, so the time step varied between each case with different rotational speed.

2.3. Convergence Criterion. For the case of the pressure ratio of 2.5, three periods were calculated, and the air intake condition was at ambient pressure and room temperature $(300 \mathrm{~K})$. The maximum pressure in the top compression chamber was recorded, and as illustrated in Figure 3, the maximum relative error of the pressure was less than $1 \%$ in the first three working processes. The periodic pressure field demonstrated the convergence of the calculation.

Figure 4 shows the $p-v$ diagram of the simulation results for the fourth working period. The simulated exhaust pressure was approximately $10 \%$ higher than the theoretical exhaust pressure $(0.25 \mathrm{MPa})$, and the simulated inlet pressure was approximately $10 \%$ lower than the inlet pressure of the atmosphere $(0.10 \mathrm{MPa})$. The results are reasonable for the working principle of the valves.

\section{Experimental Setup}

3.1. Experimental System. The leakage flow rate through the labyrinth piston in the double-acting compressor could hardly be measured in the experiment; thus, a special singleacting compressor (Figure 5) was designed. Gas was sucked through the suction valve and compressed in the bottom annular chamber by the compression piston. The compressed gas will then be discharged to the exhaust gas tank through the bottom discharge valve. In the compression 


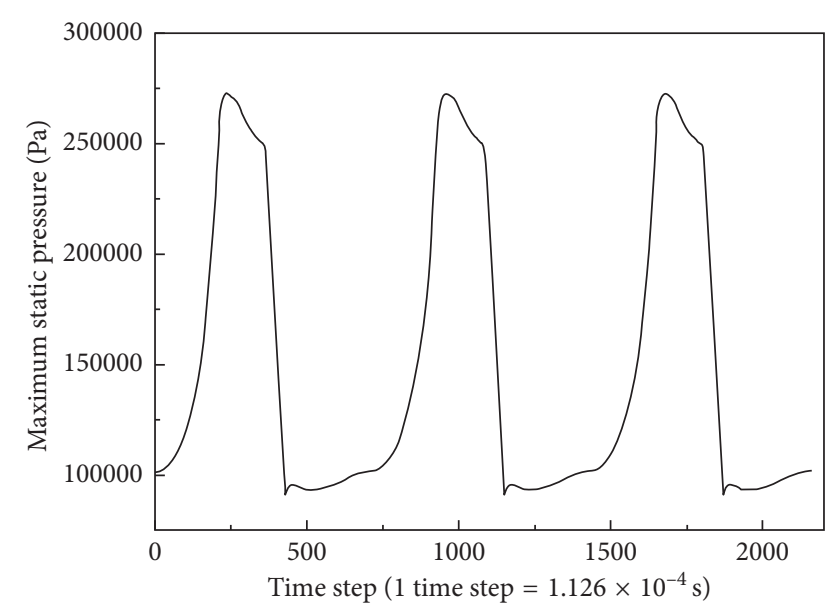

FIgURe 3: Pressure varied with the time step in the monitoring area.

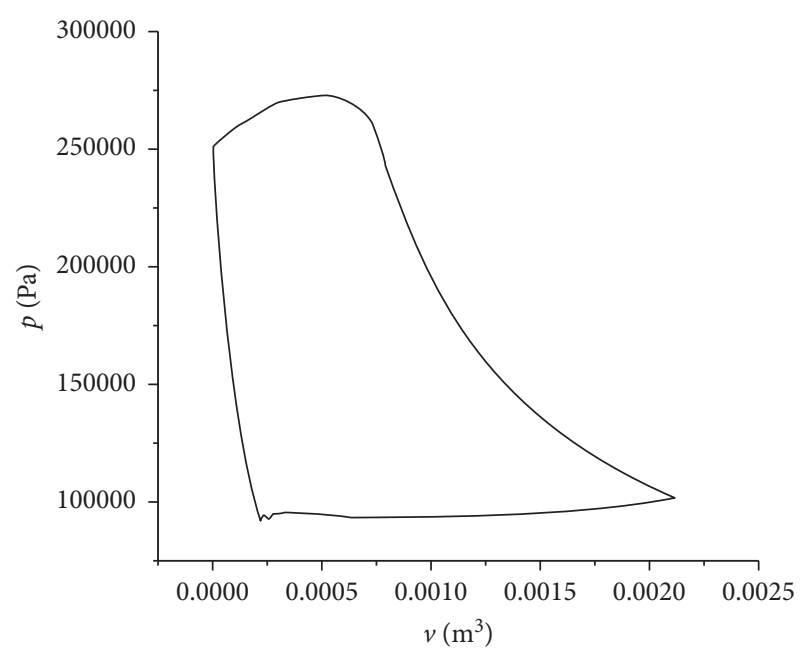

Figure 4: The simulated $p-v$ diagram.

process, the high-pressure gas will leak through the labyrinth seal between the labyrinth piston and cylinder wall and flow to the top chamber, which was linked directly to the gasholder. The nozzle flow meter was installed after the gas tank to measure the mass flow of the gas leakage. The dynamic pressure in the compression cylinder was measured by a dynamic pressure sensor and was collected through the pressure acquisition system.

Figure 6 displays the labyrinth compressor dynamic test system, and Figure 7 shows the labyrinth compressor dynamic test bench, including inverter, motor, labyrinth compressor, storage tank, nozzle flow meter, and pressure acquisition system. An inverter controlled the rotational speed of the labyrinth compressor, and a valve behind the exhaust tank regulated the exhaust pressure.

3.2. Error Analysis. In this experiment, the flow measurement errors mainly come from the following aspects:

Suction temperature error $\mu_{1}$ : the TM-902-c thermometer was adopted to measure the compressor suction temperature, in which the sensor is a $K$-thermocouple. The measuring range is $-50^{\circ} \mathrm{C} \sim 1300^{\circ} \mathrm{C}$, and the accuracy is $0.75 \%\left({ }^{\circ} \mathrm{C}^{-1}\right.$ at $\left.0{ }^{\circ} \mathrm{C} \sim 500^{\circ} \mathrm{C}\right)$.

Nozzle pressure difference error $\mu_{2}$ : for the water pressure differential gauge, whose accuracy is $\pm 10 \mathrm{~Pa}$ (or $1 \mathrm{~mm}$ ), when the measured values $\Delta p>10^{4} \mathrm{~Pa}$, the nozzle pressure difference uncertainty error is $0.1 \%$.

Nozzle upstream gas temperature error $\mu_{3}$ : for the glass rod mercury thermometer, whose temperature range is $-50^{\circ} \mathrm{C} \sim 1300^{\circ} \mathrm{C}$, the scale is 0.5 , if checked effectively, and using correctly, the absolute uncertainty of measurement value is $1.0^{\circ} \mathrm{C}$. This experiment got the minimum temperature of $20.9^{\circ} \mathrm{C}$, and the uncertainty of error is as follows:

$$
\mu_{3}<\frac{1.0}{20.9}=4.78 \%
$$

Thus, in this study, the uncertainty of the leakage measurement is as follows:

$$
\mu_{m}=\sqrt{\mu_{1}^{2}+\frac{1}{4} \mu_{2}^{2}+\frac{1}{4} \mu_{3}^{2}}=2.51 \%
$$

\section{Results and Discussion}

4.1. Experimental Validation. In this research, the relative leakage coefficient, $\alpha$, is defined as follows:

$$
\alpha=\frac{m_{s}}{m_{0}} .
$$

where $m_{0}$ represents the total mass of the theoretical compressed gas in a piston reciprocating cycle. $m_{0}$ can be calculated as

$$
m_{0}=\frac{1}{4} \pi d^{2} s \rho
$$

$m_{s}$ means the total mass of the realistic compressed gas in a piston reciprocating cycle, which is obtained from the simulation. $m_{s}$ can be calculated as

$$
m_{s}=\int_{0}^{T} \dot{m} \mathrm{dt}
$$

In this experimental study, $\alpha$ was used as the evaluation of the relative sealing performance, and a lower $\alpha$ indicates a higher labyrinth seal effect.

The test bench simulation model was set up, and all simulation methods and settings were identical to the double-acting compressor. Figures $8(a)$ and $8(b)$ display the experimental and simulation results by varying the pressure ratio and compressor rotational speed, respectively, with air as the working medium and all other conditions the same.

The relative leakage coefficient from the experiments and $\alpha$ from the simulation have a similar changing trend with the variation of the pressure ratio and rotational speed. The difference between the simulation and experimental results peaked at $13.13 \%$ and $14.13 \%$ as the pressure ratio and rotational speed varied, respectively. 


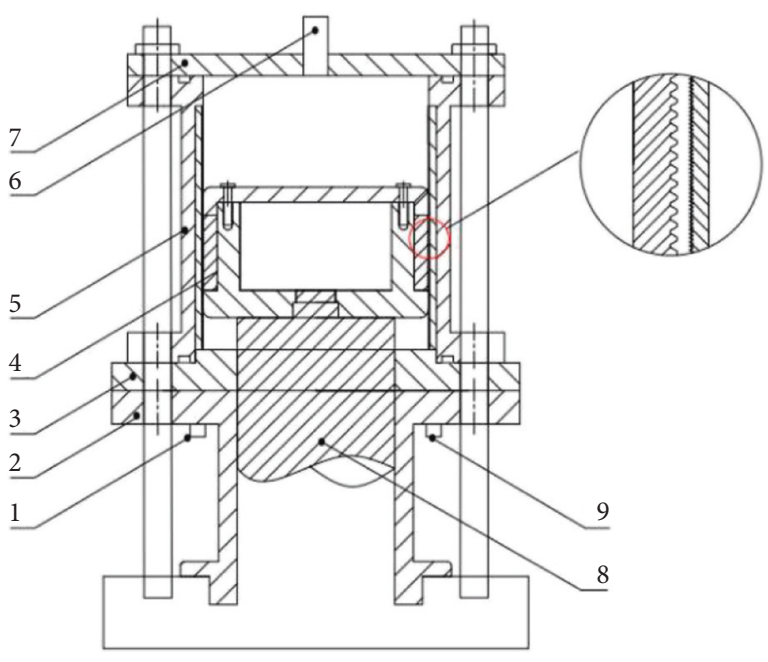

(a)

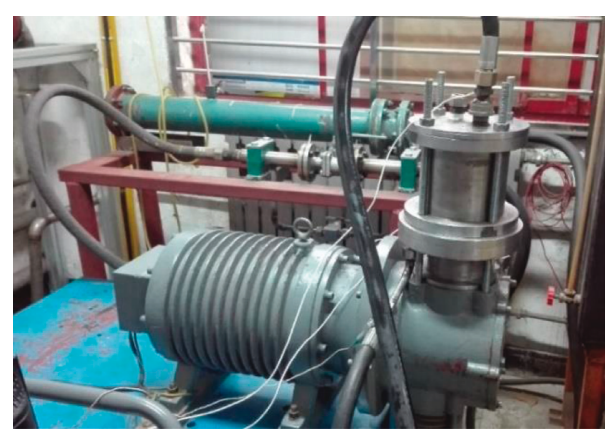

(b)

FiguRe 5: Experimental labyrinth compressor apparatus. (1) Intake valve; (2) rack; (3) valve plate; (4) labyrinth piston; (5) cylinder; (6) leakage gas outlet; (7) cover plate; (8) discharge valve; (9) compression piston.

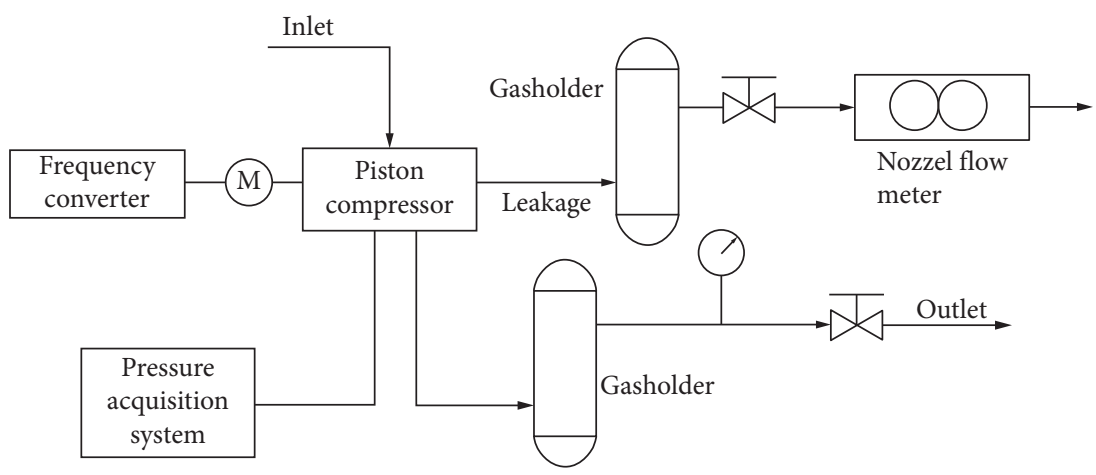

FIgURE 6: The dynamic test system of labyrinth compressor.

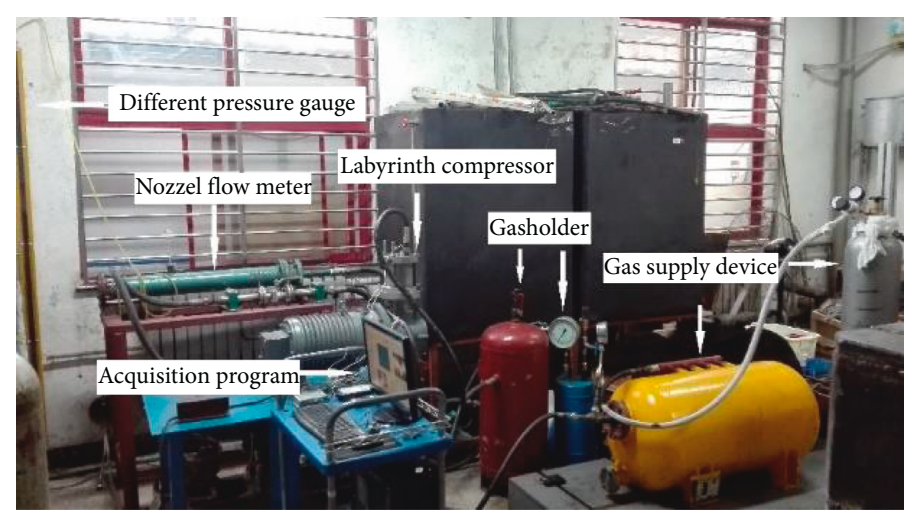

Figure 7: Test bench.

Figure 9 displays the results with a working medium of carbon dioxide. Similar to the results with air as the working medium, as the compression ratio increased, the results of the experiment and simulation showed a proportional increasing trend with the maximum deviation of $4.8 \%$. The leakage in the experiment and simulation decreased as the rotational speed increased with a maximum deviation of $6.4 \%$.

In validation experiment, there is no water cooling system surrounding the cylinder, so the temperature change in the real cylinder is not so significant, and the viscosity, which is the key factor in determining the kinetic energy 


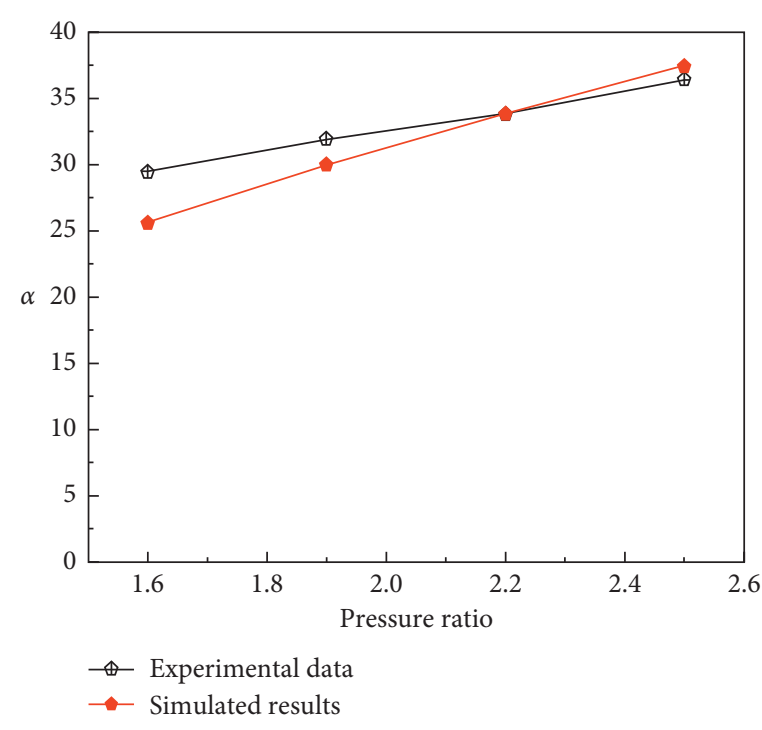

(a)

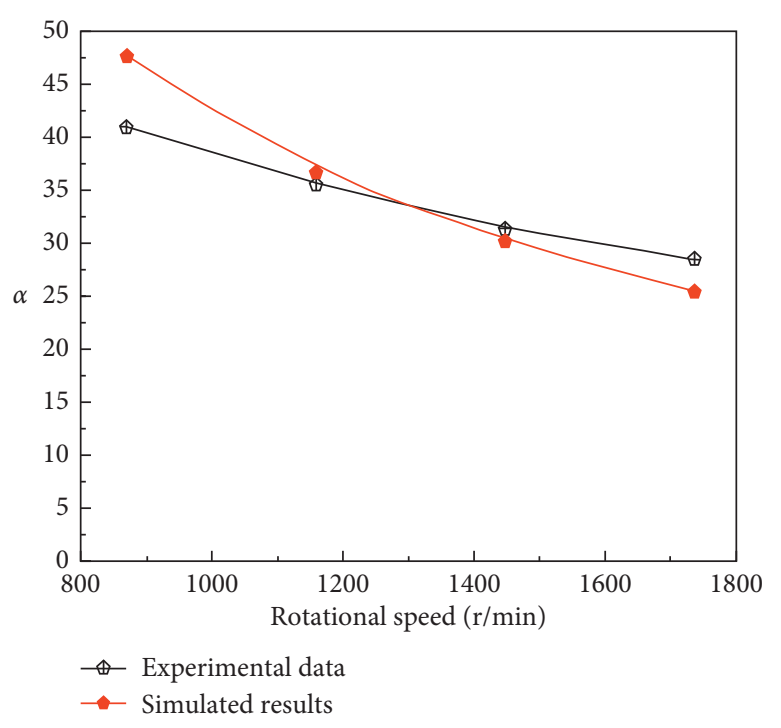

(b)

FiguRE 8: Comparison results between simulation and experiment (air as the working medium). (a) $\alpha$ versus the pressure ratio and (b) $\alpha$ versus the rotational speed.

dissipation, also has less change than that in simulation; therefore, the change of $\alpha$ in the experiment is flatter. In the same temperature and pressure, the viscosity for air is larger than that of carbon dioxide, and its change is more dramatic with the variation of the temperature and pressure, so the difference between experiment and simulation is correspondingly larger for air. In general, the simulation results correlate closely with the experimental data; thus, the dynamic simulation model accurately predicted the labyrinth seal leakage rate.

4.2. Comparison with the Steady Simulation. In our previous work, steady simulations were done to study the effects of the structural parameters of the labyrinth cavity [22]. Taking the final leakage flow rate value as the average leakage flow rate in one compression period for the steady simulation, $\alpha$ of the steady and the transient simulations was compared, and when the working medium was air, the rotational speed was $740 \mathrm{r} / \mathrm{min}$, the inlet pressure was $0.1 \mathrm{MPa}$, and the pressure ratio was 2.5. $\alpha$ for the steady and transient simulations was $28.21 \%$ and $12.63 \%$, respectively. The relative deviation between these two cases was $55.23 \%$. In the actual case, the reciprocating piston moved continuously, affecting the leakage flow through the labyrinth seal, and the pressure ratio of the two chambers also changed constantly not keeping the constant value as the theoretical pressure ratio, 2.5. Thus, the leakage of the steady simulation was significantly higher than the actual case.

Figure 10 shows the pressure in the labyrinth channel and division of the velocity field in the steady simulation [22]. In the transient simulation, when the crank angle was $105^{\circ}$, the piston moved to the middle of the cylinder. The top chamber was the high-pressure chamber and the bottom chamber was the low-pressure chamber, with a pressure ratio of 2.5. Under these conditions, the flow field is comparable to the steady simulation. The pressure field and the velocity field of the transient simulation are as shown in Figures 11 and 12, respectively.

The velocity field in Regions A, B, and C of the steady and transient simulation models is shown in Figure 13. The velocity and vortex of the velocity in Region $\mathrm{A}$ approximate Region B. However, with airflow to Region C and flow through the labyrinth clearance, the velocity for the steady simulation was minimally higher than the transient simulation. A maximum difference of $8 \%$ was observed between the steady and the transient simulations. This deviation was attributed to the movement of the piston preventing leakage flow timely and totally through the labyrinth clearance. The pressure ratio and the pressure difference between the two sides of the labyrinth channel changed all the time in the working process. Thus, the steady simulation accurately represented the sealing performance under specific pressure ratios. However, the results of the steady simulation were not valid for the complete compression process in the real reciprocating piston compressor.

\subsection{Relationship between Leakage and Pressure Ratio.} Figure 14 illustrates that with air as the working medium, the relative leakage coefficient increased linearly with an increase in the pressure ratio, $\varepsilon$, at an inlet pressure of $0.1 \mathrm{MPa}$ and $1 \mathrm{MPa}$. When the pressure ratio increased from 1.5 to $4.0, \alpha$ increased by approximately $12 \%$. Thus, an increase of 0.5 in the pressure ratio resulted in a $2.4 \%$ increase in $\alpha$.

At a crank angle of $300^{\circ}$, the bottom chamber was compressing air and the top chamber was sucking air, the 


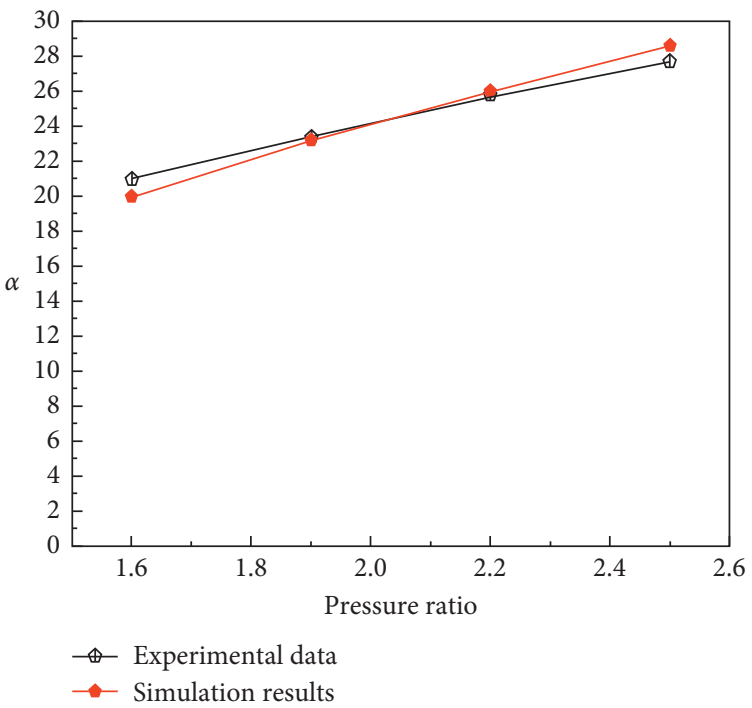

(a)

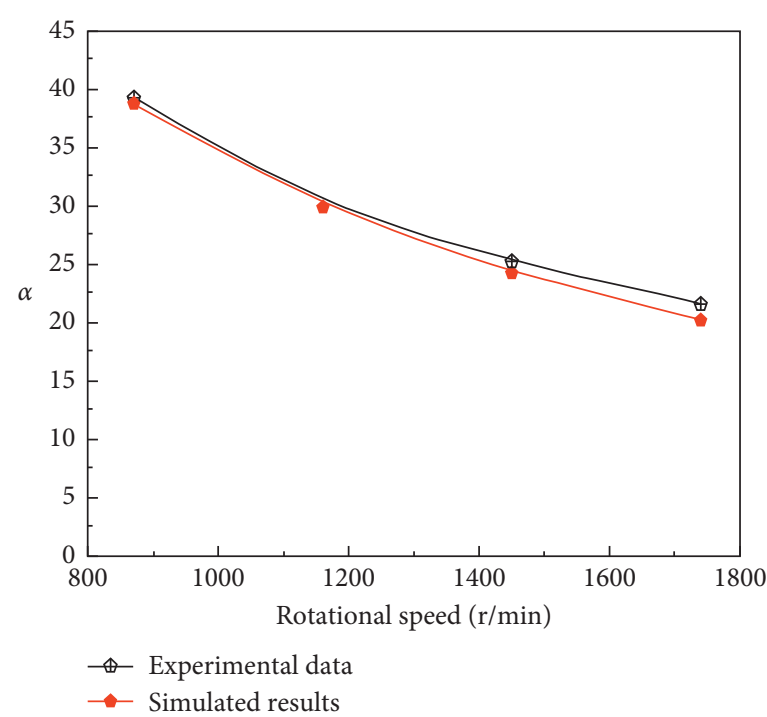

(b)

FIGURE 9: Comparison results between simulation and experiment (carbon dioxide as the working medium). (a) $\alpha$ versus pressure ratio and (b) $\alpha$ versus rotational speed.

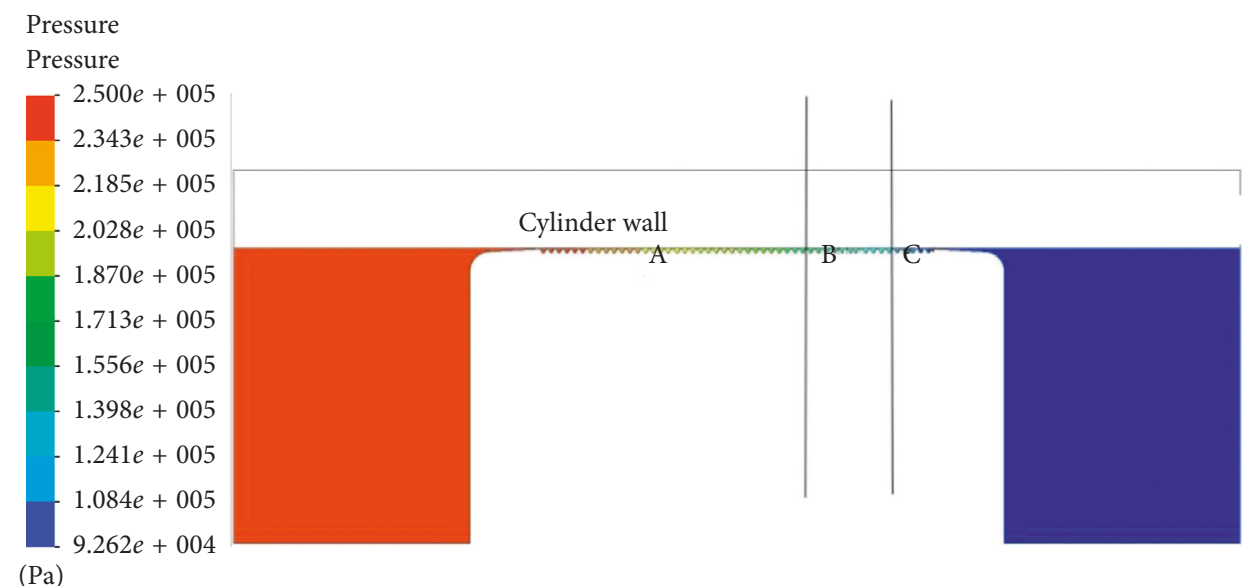

FIGURE 10: Pressure in the labyrinth seal and the division of the velocity field.

discharge valve opened, and the pressure in the bottom chamber was the exhaust pressure. The velocity vector field for a pressure ratio of 1.5 and 4.0 with the intake pressure of $0.1 \mathrm{MPa}$ is shown in Figures $15(\mathrm{a})$ and $15(\mathrm{~b})$, respectively. As noted in these figures, the high-pressure air leaked to the top chamber through the labyrinth seal, and at an $\varepsilon$ of 1.5 and 4.0 , the velocity was approximately $10 \mathrm{~m} / \mathrm{s}$ and $38 \mathrm{~m} / \mathrm{s}$, respectively. Higher pressure ratio led to higher leakage velocity, and higher leakage velocity resulted in an increased leakage rate at a constant rotational speed.

Increasing the inlet pressure from $0.1 \mathrm{MPa}$ to $1.0 \mathrm{MPa}$ increased $\alpha$ by approximately 12\%. Compressed gas will leak along the leakage channel driven by the pressure difference, and the greater the driving force, the larger the gas leakage flow rate. At a constant compression ratio, the pressure difference was higher on both sides of the piston at a higher inlet pressure, so the sealing performance became worse.

4.4. Relationship between Leakage and Rotational Speed. Figure 16 shows that with $\varepsilon$ of 2.5 for air compression when $r$ increased from $500 \mathrm{r} / \mathrm{min}$ to $1000 \mathrm{r} / \mathrm{min}, \alpha$ decreased by nearly $50 \%$. In this case, each increase of $100 \mathrm{r} / \mathrm{min}$ in $r$ caused the relative leakage rate to be reduced by approximately $0.09 \%$.

Figures 17 (a)-17(c) show the velocity field at a rotational speed of $500 \mathrm{r} / \mathrm{min}, 800 \mathrm{r} / \mathrm{min}$, and $1000 \mathrm{r} / \mathrm{min}$, respectively, when the piston is at the position with the crank angle of $270^{\circ}$. The piston was moving downward, and the velocity was $3.14 \mathrm{~m} / \mathrm{s}, 5.03 \mathrm{~m} / \mathrm{s}$, and $6.28 \mathrm{~m} / \mathrm{s}$ at $500 \mathrm{r} / \mathrm{min}, 800 \mathrm{r} / \mathrm{m}$, and $1000 \mathrm{r} / \mathrm{min}$, respectively. The leakage velocity at the outlet of the leak channel was approximately $15 \mathrm{~m} / \mathrm{s}$ in all cases. The maximum speed difference was $8 \%$, so when the pressure 


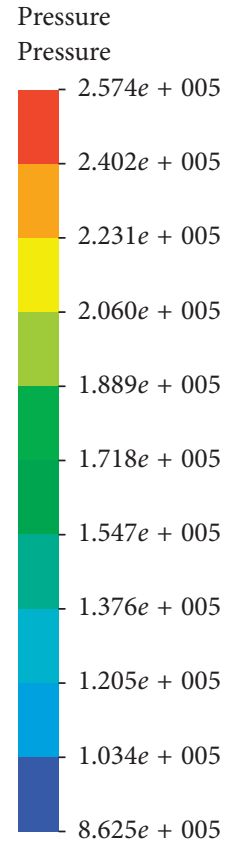

(Pa)

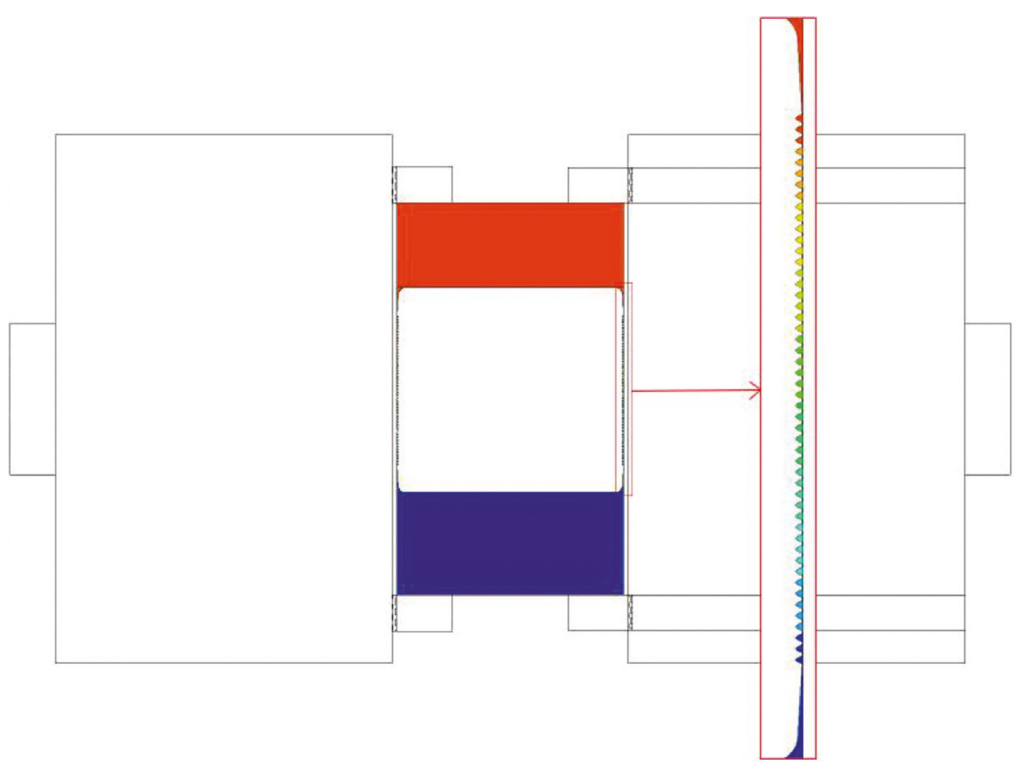

FIgURE 11: Pressure field at the crank angle of $105^{\circ}$.

Velocity vector
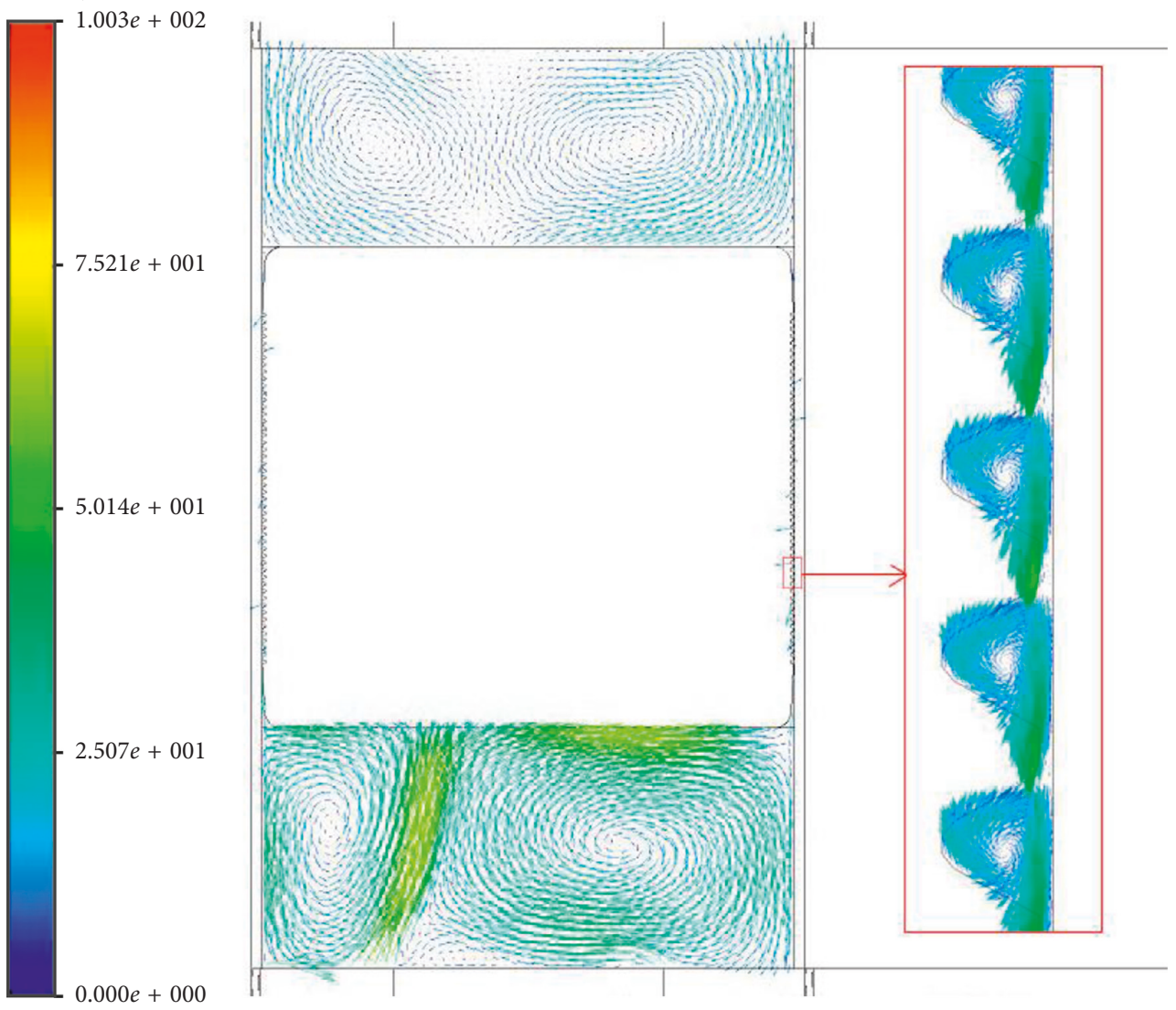

$\left(\mathrm{ms}^{-1}\right)$

FIgURE 12: Velocity field at the crank angle of $105^{\circ}$. 


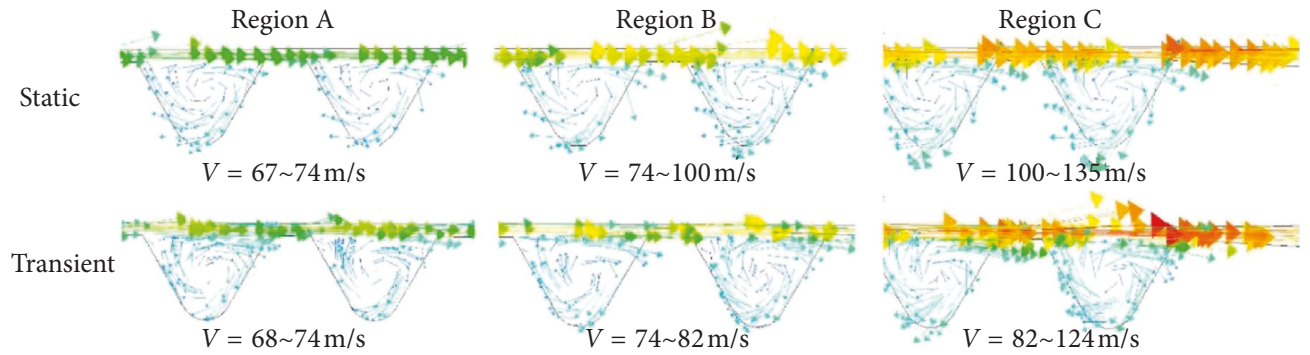

Figure 13: Velocity field in Regions A, B, and C of the steady and transient simulation.

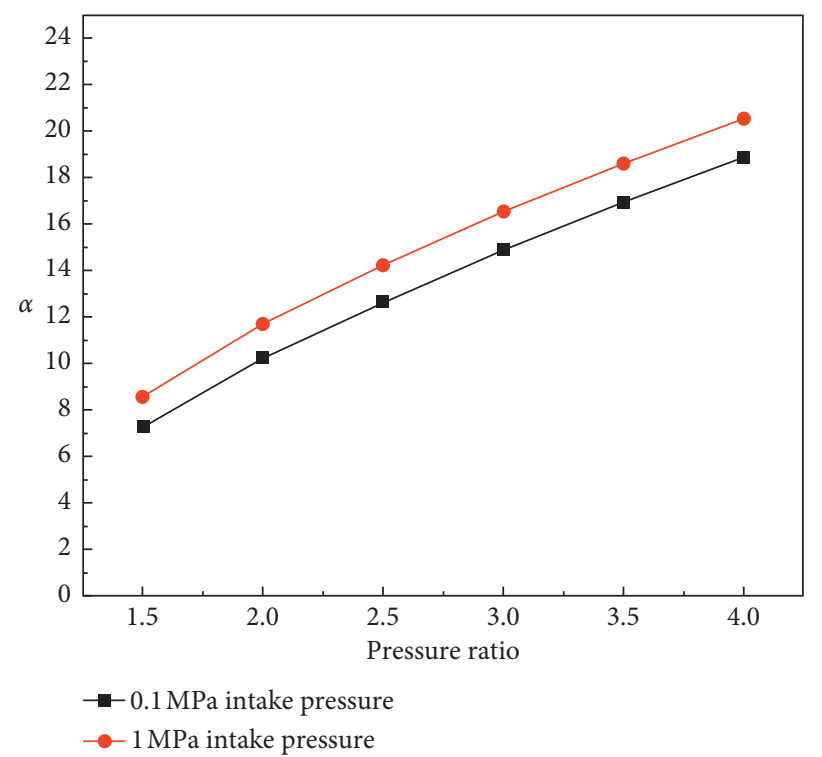

Figure 14: $\alpha$ versus pressure ratio.

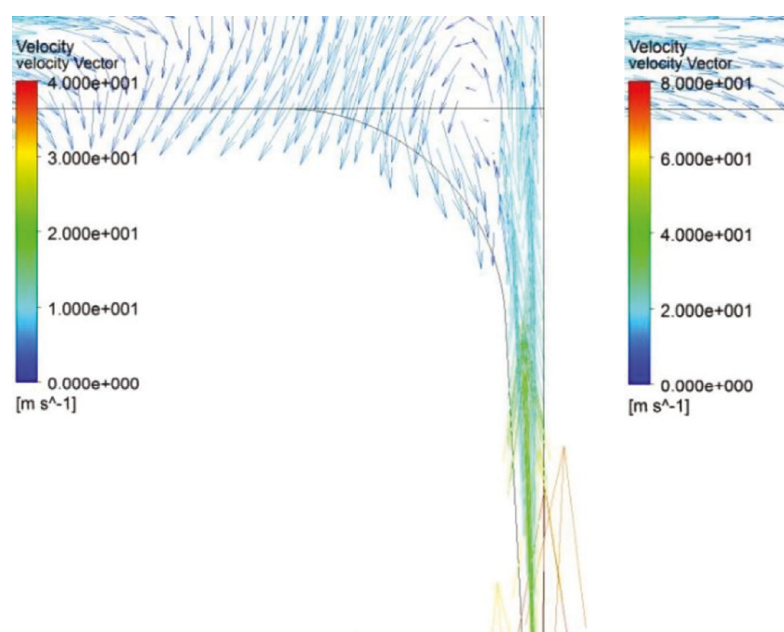

(a)

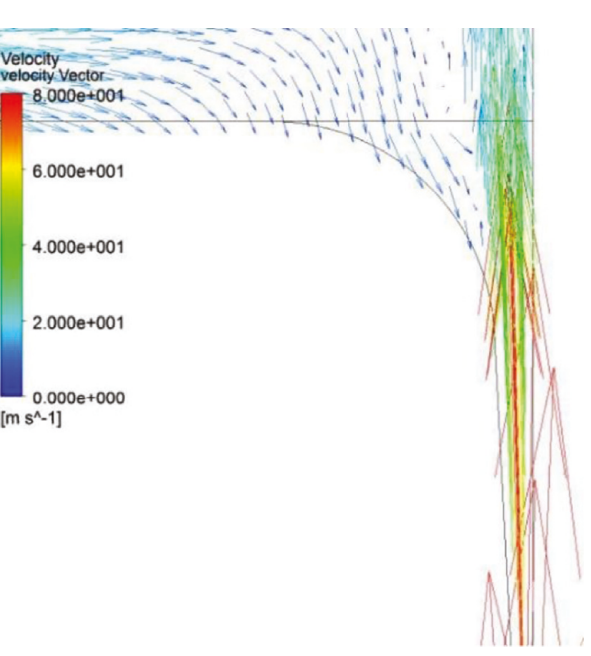

(b)

FigURE 15: Velocity vector field at an intake pressure of $0.1 \mathrm{MPa}$. (a) $\varepsilon=1.5$ and (b) $\varepsilon=4.0$.

ratio on the two sides kept the same, the leak velocity on the outlet remained almost constant as piston speed varied. However, at increased rotational speeds, the air in the compressor had less leakage time, and that would result in a relatively lower relative leakage coefficient.
The curves in Figure 16 illustrate that the decreasing trend in leakage with an increase in rotational speed is gradually becoming insignificant. Thus, the increase in sealing performance as the compressor speed increases would reach a critical value where increasing rotational 


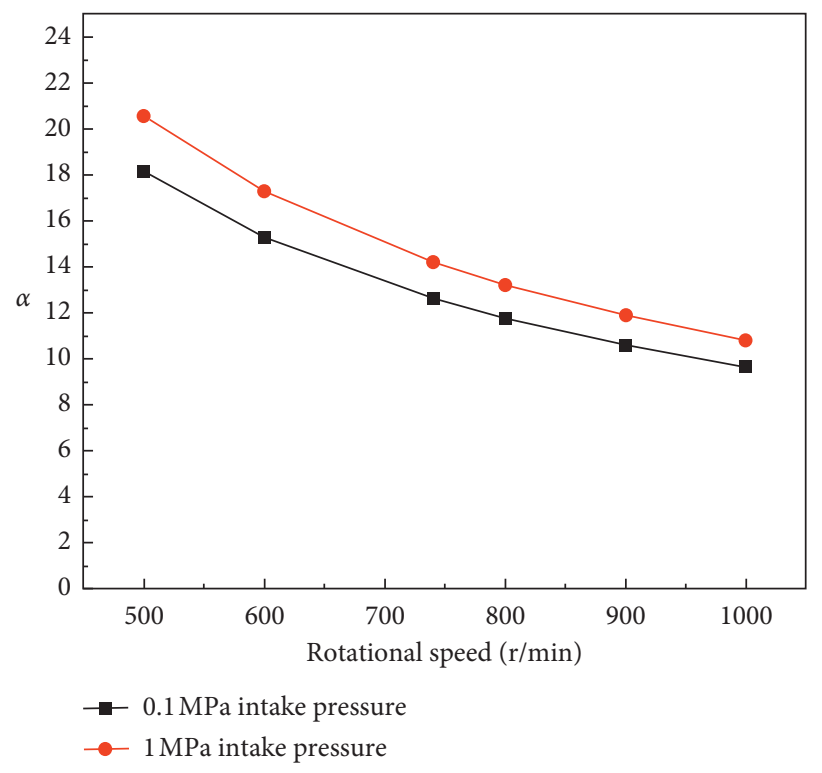

FIGURE 16: $\alpha$ versus rotational speed.

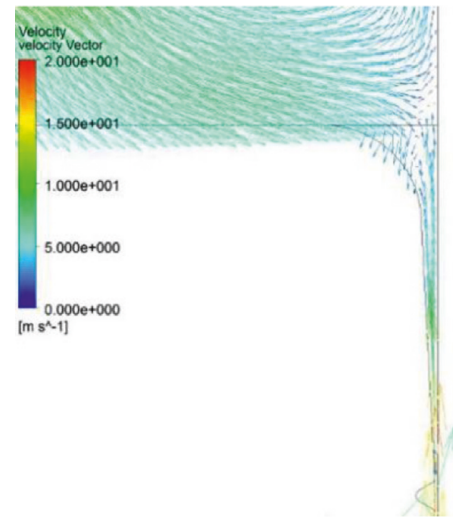

(a)

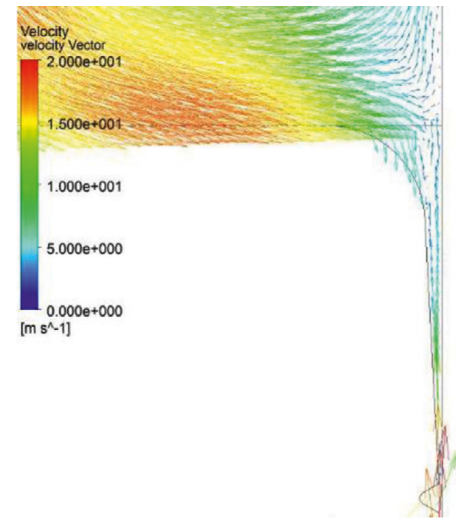

(b)

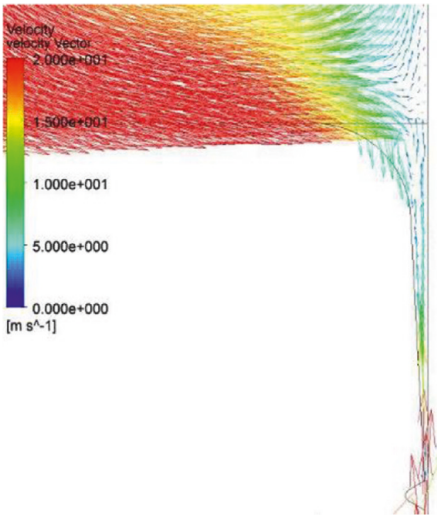

(c)

FIGURE 17: Velocity vector for the compressor at various rotational speeds. (a) $500 \mathrm{r} / \mathrm{min}$, (b) $800 \mathrm{r} / \mathrm{min}$, and (c) $1000 \mathrm{r} / \mathrm{min}$.

speed had an insignificant effect on sealing performance. Therefore, when the pressure ratio and the structure of the compressor are defined, there is a limit on the decrease in leakage rate as the rotational speed increases.

\subsection{Relationship between Leakage and Working Medium.} Figure 18 displays the effect of several working mediums on leakage performance of the labyrinth compressor when $\varepsilon$ is 2.5 with $0.1 \mathrm{MPa}$ intake pressure and the rotational speed is $740 \mathrm{r} / \mathrm{min}$. As illustrated in this figure, the relative leakage coefficient from high to low was ammonia, nitrogen, oxygen, propane, propylene, and carbon dioxide. An insignificant variation occurred in the sealing performance of oxygen, propane, propylene, and carbon dioxide.
As shown in Figure 18, the relative leakage gradually decreased as the relative molecular mass increased, so the leakage performance can be predicted by the relative molecular mass of the working medium. However, for the working mediums that had the same relative molecular mass, such as carbon dioxide and $\mathrm{C}_{3} \mathrm{H}_{8}$, the relative leakage for carbon dioxide was less than $\mathrm{C}_{3} \mathrm{H}_{8}$. Therefore, the sealing performance was also affected by the viscosity and density of the working medium.

4.6. Relationship between Leakage and Clearance Volume. When $\varepsilon$ is 2.5 , the intake pressure is $0.1 \mathrm{MPa}$ and the rotational speed is $740 \mathrm{r} / \mathrm{min}$. Figure 19 shows that the relative leakage coefficient remains nearly constant as the clearance volume increases in the reciprocating air compressor. In a compressor clearance volume range of $10 \%$ to $20 \%$, the 


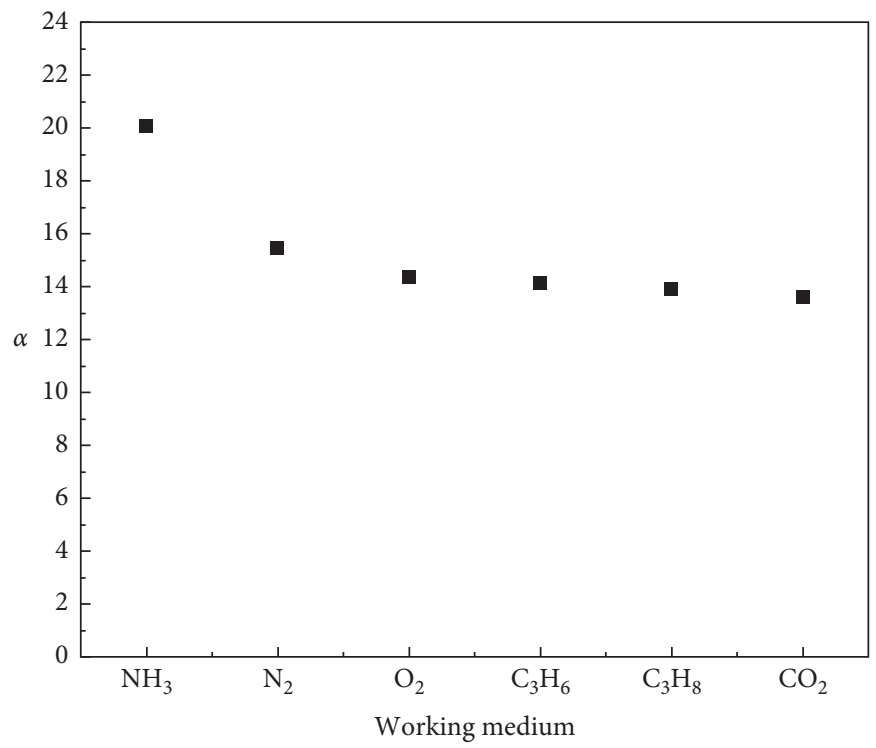

Figure 18: $\alpha$ versus working medium.

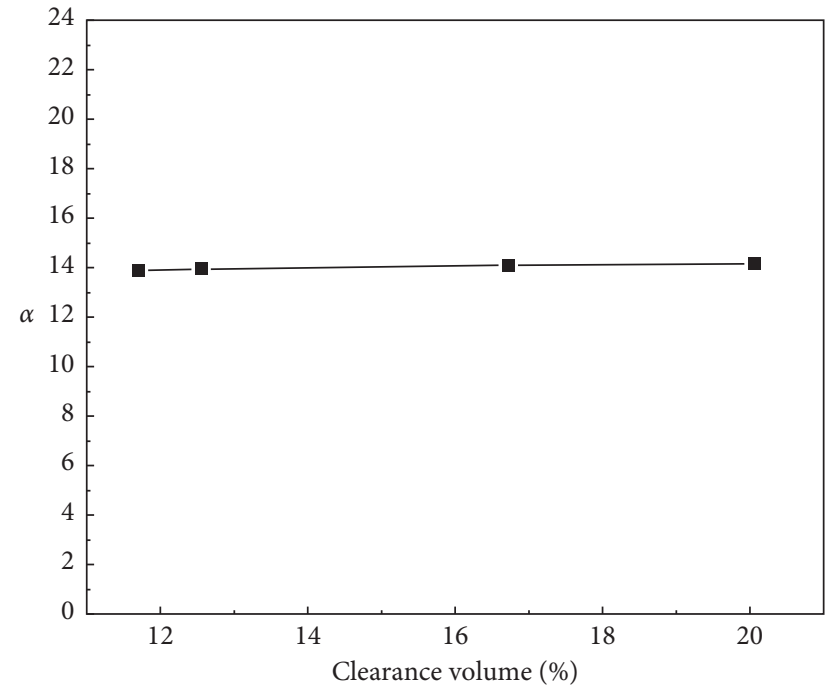

Figure 19: $\alpha$ versus clearance volume.

relative leakage was $12 \%$ to $14 \%$, demonstrating the negligible effect of the clearance volume on leakage.

\section{Conclusions}

By comparing the transient and steady simulation result, it shows that the dynamic simulation is necessary to obtain a realistic leakage flow rate. The leakage calculated by the transient simulation was consistent with the experimental data; therefore, the transient model with multiscale dynamic mesh is reasonable for predicting the real leakage performance in the labyrinth compressor. Based on the results of this investigation, the effects of various parameters are as follows:

(1) Increasing the compression ratio resulted in a linear increase in the relative leakage with a 0.5 increase in $\mathcal{E}$, increasing $\alpha$ by $2.4 \%$. With a constant compression ratio, the leakage in the high-pressure inlet $(1 \mathrm{MPa})$ compressor was relatively higher (10\%) than that in the low-pressure inlet $(0.1 \mathrm{MPa})$ compressor.

(2) The relative leakage coefficient sharply decreased as rotational speed increased. Increasing rotational speed from $500 \mathrm{r} / \mathrm{min}$ to $1000 \mathrm{r} / \mathrm{min}$ resulted in a decrease in relative leakage by approximately $50 \%$. As the rotational speed increased above $1000 \mathrm{r} / \mathrm{min}$, the downtrend of the relative leakage rate became slow.

(3) Sealing performance that varied for the working mediums was tested. Gases studied were hydrogen, nitrogen, oxygen, propane, propylene, and carbon dioxide. The poorest sealing performance was with ammonia followed by nitrogen. The other three gases showed a negligible difference in leakage amount. The $\alpha$ decreased as the relative molecular mass increased.

\section{Data Availability}

All data are provided in full in the results section of this paper.

\section{Conflicts of Interest}

The authors have no conflicts of interest to declare.

\section{Acknowledgments}

This work was supported by the Natural Science Foundation of Shaanxi Province (Research Project 2016JQ5114) and the China Postdoctoral Science Foundation (Grant no. 2018M643639).

\section{References}

[1] J. Larjola, J. Honkatukia, P. Sallinen, and J. Backman, "Fluid dynamic modeling of a free piston engine with labyrinth seals," Journal of Thermal Science, vol. 19, no. 2, pp. 141-147, 2010.

[2] F. Cangioli, P. Pennacchi, G. Vannini, and L. Ciuchicchi, "Effect of energy equation in one control-volume bulk-flow 
model for the prediction of labyrinth seal dynamic coefficients," Mechanical Systems and Signal Processing, vol. 98, pp. 594-612, 2018.

[3] F. Cangioli, P. Pennacchi, G. Vannini et al., "On the thermodynamic process in the bulk-flow model for the estimation of the dynamic coefficients of labyrinth seals," Journal of Engineering for Gas Turbines and Power, vol. 140, no. 3, Article ID 032502, 2018.

[4] B. Hodkinson, "Estimation of the leakage through a labyrinth gland," Proceedings of the Institution of Mechanical Engineers, vol. 141 , no. 1, pp. 283-288, 1939.

[5] L. M. Milne-Thomson, Theoretical Hydrodynamics, St. Martin's Press, New York, NY, USA, 4th edition, 1960.

[6] G. Vermes, "A fluid mechanics approach to the labyrinth seal leakage problem," Journal of Engineering for Power, vol. 83, no. 2, pp. 161-169, 1961.

[7] M. Alizadeh, B. Nikkhahi, A. S. Farahani, and A. Fathi, "Numerical study on the effect of geometrical parameters on the labyrinth-honeycomb seal performance," Proceedings of the Institution of Mechanical Engineers, Part G: Journal of Aerospace Engineering, vol. 232, no. 2, pp. 362-373, 2018.

[8] J. A. Demko, G. L. Morrison, and D. L. Rhode, "The prediction and measurement of incompressible flow in a labyrinth seal," Journal of Engineering for Gas Turbines and Power, vol. 111, no. 4, pp. 697-702, 1989.

[9] H. L. Stocker, "Determining and improving labyrinth seal performance in current and advanced high performance gas turbines," in Proceedings of the AGARD Conference on Seal Technology in Gas Turbine Engines, 1978.

[10] S. Suryanarayanan and G. L. Morrison, "Effect of tooth height, tooth width and shaft diameter on carry-over coefficient of labyrinth seals," in Proceedings of the ASME Turbo Expo 2009: Power for Land, Sea, and Air, pp. 1147-1152, American Society of Mechanical Engineers (ASME), Orlando, FL, USA, June 2009.

[11] S. Suryanarayanan and G. L. Morrison, "Labyrinth seal discharge coefficient for rectangular cavities," in Proceedings of the ASME 2009 Fluids Engineering Division Summer Meeting, pp. 99-114, American Society of Mechanical Engineers (ASME), Vail, Colorado, USA, August 2009.

[12] S. Suryanarayanan and G. L. Morrison, "Analysis of flow parameters influencing carry-over coefficient of labyrinth seals," in Proceedings of the ASME Turbo Expo 2009: Power for Land, Sea, and Air, pp. 1137-1145, American Society of Mechanical Engineers (ASME), Orlando, FL, USA, June 2009.

[13] W.-z. Wang, Y.-z. Liu, P.-n. Jiang, and H.-p. Chen, "Numerical analysis of leakage flow through two labyrinth seals," Journal of Hydrodynamics, vol. 19, no. 1, pp. 107-112, 2007.

[14] S. Wittig, U. Schelling, S. Kim, and K. Jacobsen, "Numerical predictions and measurements of discharge coefficients in labyrinth seals," in Proceedings of the ASME 1987 International Gas Turbine Conference and Exhibition, May-June 1987.

[15] T. S. Kim and K. S. Cha, "Comparative analysis of the influence of labyrinth seal configuration on leakage behavior," Journal of Mechanical Science and Technology, vol. 23, no. 10, pp. 2830-2838, 2009.

[16] W. Zhao, T. K. Nielsen, and J. T. Billdal, "Effects of cavity on leakage loss in straight-through labyrinth seals," IOP Conference Series: Earth and Environmental Science, vol. 12, Article ID 012002, 2010.

[17] L. Bozzi, E. D’Angelo, B. Facchini, M. Micio, and R. Da Soghe, "Experimental investigation on leakage losses and heat transfer in a non conventional labyrinth seal," in Proceedings of the ASME 2011 Turbo Expo: Turbine Technical Conference and Exposition, pp. 955-965, American Society of Mechanical Engineers (ASME), Vancouver, British Columbia, Canada, June 2011.

[18] J. Cheng, X. Zeng, Z. Liu, X. Yu, and Q. Feng, "Research on dynamic modeling and electromagnetic force centering of piston/piston rod system for labyrinth piston compressor," Proceedings of the Institution of Mechanical Engineers, Part I: Journal of Systems and Control Engineering, vol. 230, no. 8, pp. 786-798, 2016.

[19] J. Cheng, M. Zhang, Z. Liu, Q. Feng, and X. Zeng, "Research on the piston precise electromagnetic centering of labyrinthpiston compressor," Proceedings of the Institution of $\mathrm{Me}$ chanical Engineers, Part A: Journal of Power and Energy, vol. 230, no. 4, pp. 388-401, 2016.

[20] H. N. Tang, H. Yao, S. J. Wang, X. S. Meng, H. T. Qiao, and J. H. Qiao, "Numerical simulation of leakage rates of labyrinth seal in reciprocating compressor," IOP Conference Series: Materials Science and Engineering, vol. 164, Article ID 012015, 2017.

[21] A. Schaller, N. Darvishsefat, and E. Schlücker, "Simulation and experimental investigation of labyrinth seals for reciprocating piston compressors," Chemical Engineering \& Technology, vol. 41, no. 5, pp. 1043-1050, 2018.

[22] J. Feng, L. Wang, H. Yang, and X. Peng, "Numerical investigation on the effects of structural parameters of labyrinth cavity on sealing performance," Mathematical Problems in Engineering, vol. 2018, Article ID 5273582, 12 pages, 2018.

[23] K. Graunke and J. Ronnert, "Dynamic behavior of labyrinth seals in oilfree labyrinth-piston compressors," in Proceedings of the International Compressor Engineering Conference, Purdue University, West Lafayette, IN, USA, July 1984.

[24] T.-H. Shih, W. W. Liou, A. Shabbir, Z. Yang, and J. Zhu, "A new $k-\varepsilon d$ eddy viscosity model for high Reynolds number turbulent flows," Computers \& Fluids, vol. 24, no. 3, pp. 227-238, 1995. 


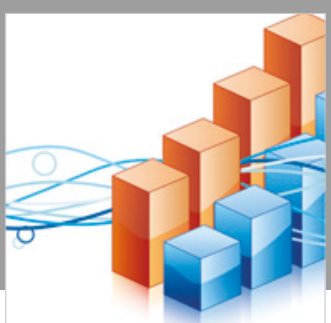

Advances in

Operations Research

\section{-n-m}
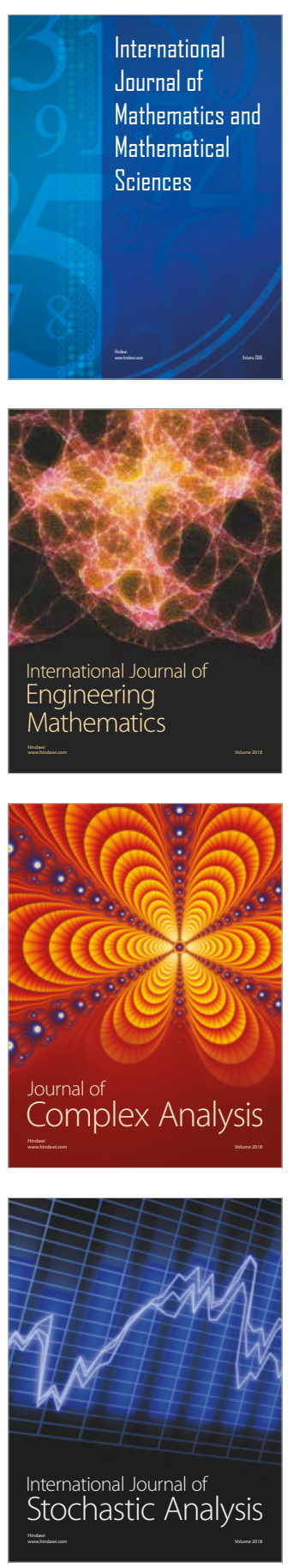
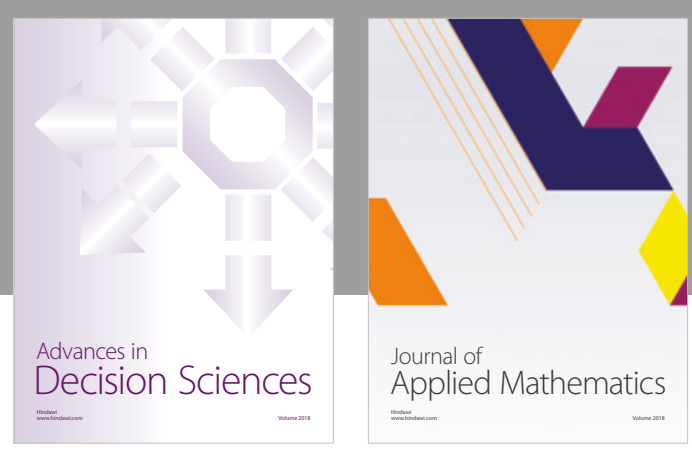

Journal of

Applied Mathematics
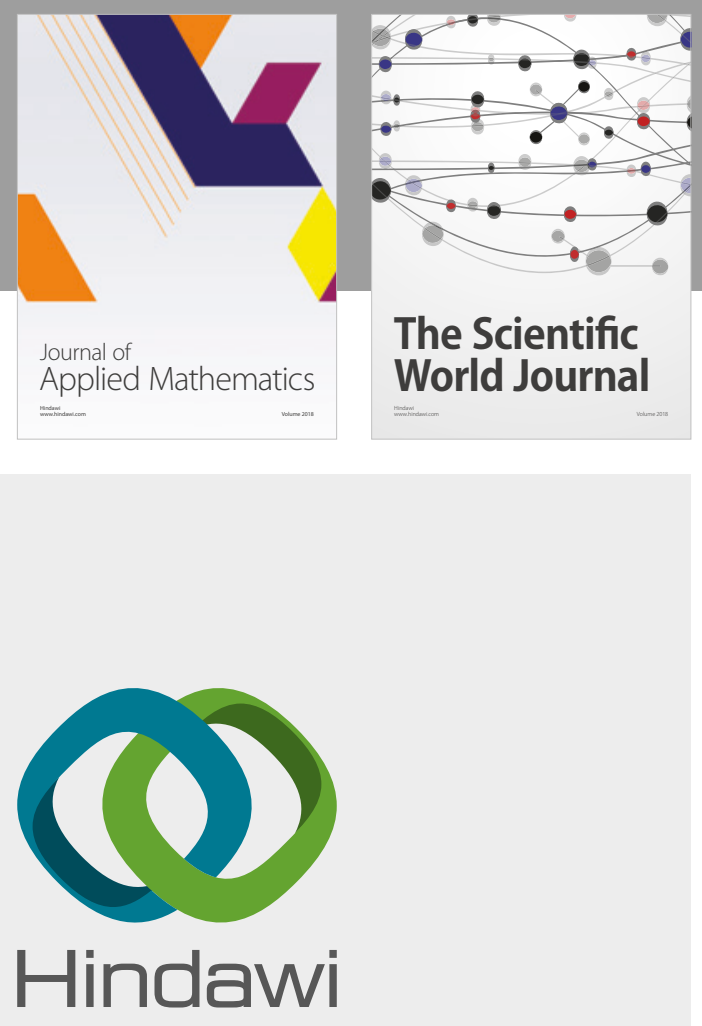

Submit your manuscripts at

www.hindawi.com

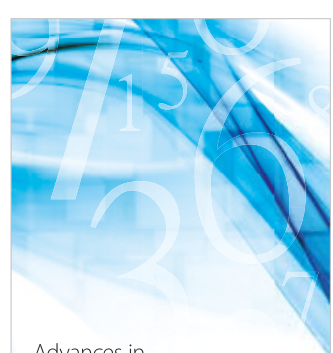

Advances in
Numerical Analysis
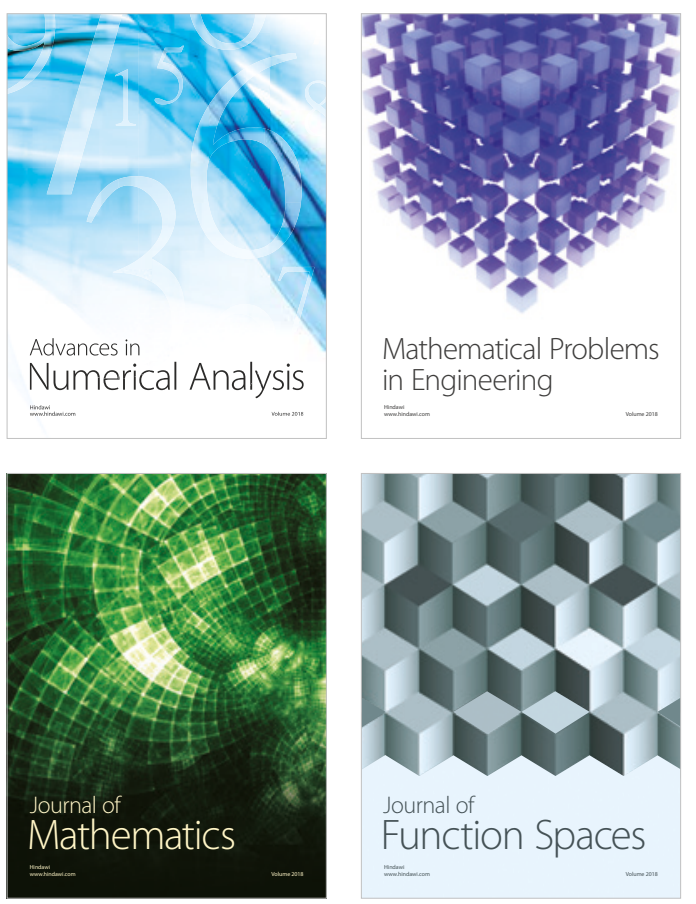

Mathematical Problems in Engineering

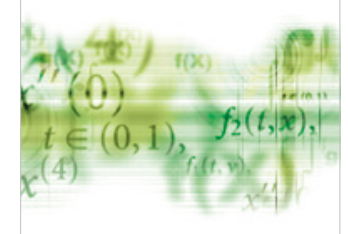

International Journal of

Differential Equations

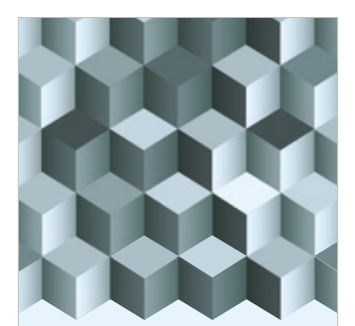

Journal of

Function Spaces

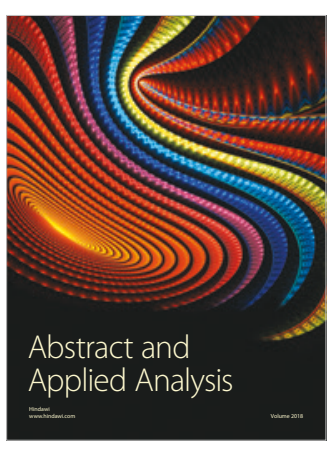

The Scientific

World Journal

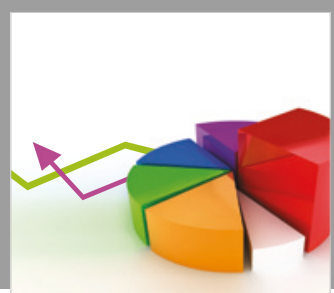

Journal of

Probability and Statistics
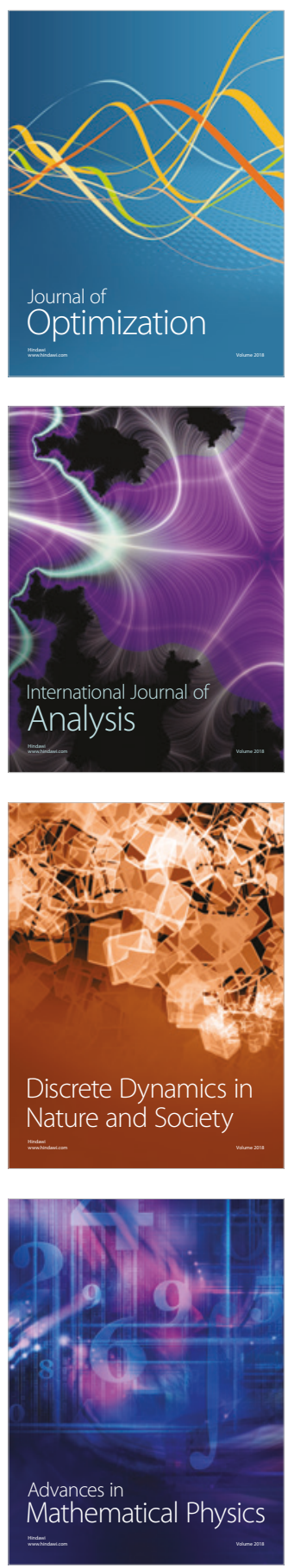